This PDF is a selection from a published volume from the National Bureau of Economic Research

Volume Title: Innovation Policy and the Economy, Volume 2

Volume Author/Editor: Adam B. Jaffe, Josh Lerner and Scott Stern, editors

Volume Publisher: MIT Press

Volume ISBN: 0-262-60045-5

Volume URL: http://www.nber.org/books/jaff02-1

Conference Date: April 17, 2001

Publication Date: January 2002

Title: Prospects for an Information-Technology-Led Productivity Surge

Author: Timothy F. Bresnahan

URL: http://www.nber.org/chapters/c10787 


\section{Prospects for an Information-Technology-Led Productivity Surge}

Timothy F. Bresnahan, Stanford University and NBER

\section{Executive Summary}

Information technology (IT) is enabling; without the invention of useful applications it is of little value. Some of the most valuable applications are themselves remarkable inventions. This means that advances in IT shift the invention-possibility frontier of the economy, permitting users of IT to invent new and sometimes highly valuable applications, rather than directly shifting the production-possibility frontier of the economy. IT is also general purpose technology, shared across a wide variety of uses. New advances in IT can therefore have an economy-wide impact, which will be larger or smaller according to the degree of sharing. Finally, IT has the possibility of substantial network effects. Together, these three features of IT mean that advances in it can have very substantial impacts on long-run growth. The pace of arrival of that growth varies across types of IT, however, according to the value of the enabled applications, the difficulty of the enabled invention (co-invention), the ease of sharing advances, and the mechanisms for turning network effects into a force for advance rather than for inertia. These are complex forces, but analytical studies of earlier IT advances suggest that there are two main patterns of the pace of uptake. Current IT advances connected to the Internet seem highly likely to set off both patterns as well, so that understanding the pace of aggregate value creation involves careful analysis of which pattern applies to what. So, too, does policy formation to encourage widespread value creation.

\section{Introduction}

The welfare benefits of information technology (IT) are a subject of much debate, with scholars and policy analysts attempting to understand the relationship between IT innovation and productivity. Much of this work neglects two of the most important features of IT in use, neither of which is well captured by traditional models of the gains from innovation. In the traditional model, new goods and services are developed by vendors in response to perceived market demand or new 
technological opportunities, and the value created by innovation arises as users passively choose to buy the intrinsically valuable new technologies. In the context of IT, however, two key forces arise. First, IT does not directly shift the production function of the firm that uses it. Instead, IT is an enabling technology that permits users to invent valuable new uses. This co-invention often involves investment in business and organizational change by the users if the IT application is to be successful. ${ }^{1}$ New IT technologies create value by shifting the invention-possibility frontier of the economy, setting off waves of valuable co-invention. Second, the value of IT often depends on network effects, in which the ultimate value to users of a technology depends on the breadth of its use by other users and on the nature of other users' applications. The welfare benefits of IT are not a matter of bits and bytes and baud rates, but rather of co-invention and coordination among users.

While most analyses of the "new economy" tend to assume that the drivers of innovation are similar, there are actually two key types of IT demand segments, each of which involves a distinct set of challenges for firms and policymakers. In the first, new technologies potenially offer tremendous benefits to using firms, but there are large co-invention costs for these potential adopters. While the historical example of this type of pattern is organizational computing, the Internet has created an opportunity for interorganizational computing, in part explaining both the tremendous promise and the slow start to e-commerce. In the second type of demand segment, key technological advances yield little value unless they are widely adopted. Once widespread adoption can be achieved, however, large value to society follows, often without substantial co-invention costs. While the historical model for this is the personal computer, the emerging example is mobile computing.

The general purpose technology (GPT) nature of IT invention and co-invention promise large returns in the long run. ${ }^{2}$ Co-invention and network effects are sources of substantial social increasing returns to scale to IT. Partly this follows from external effects among users, and partly it is because widespread use of the same IT in a number of different uses creates a market opportunity for further invention and technical progress in IT itself. When the social increasing returns to scale to a particular new IT technology are realized, we see economy-wide productivity advances. ${ }^{3}$ Repeated and sustained exploitation of a sequence of new IT technologies' social increasing returns implies sustained productivity growth. My enquiry is into the pace of arrival of those benefits and its dependencies on economic conditions and policies. For 
that purpose, I review the main forces affecting the pace of adoption and value creation in IT, look at how those forces have played out historically in different segments of demand, then turn to the likely implications for the future and for policy formation.

\section{Sources of Adoption Dynamics and Value}

This section looks at the implications of network effects and co-invention for adoption dynamics and value creation. ${ }^{4}$ I first look at a specific "technology" in the sense that engineers use the term-a technology such as web-enabled cell phones, instant messaging, or Java. The economic returns to any particular technology are higher the more it is used, and this induces an important (positive) feedback from widespread usage to more rapid technical progress. This particular feedback loop can be anticipatory, as technologists will invent faster if there is a larger market in the present or if they anticipate a larger market in the future. Any of several market mechanisms can be behind this feedback, including monopoly and competition, each in several forms. ${ }^{5}$

Users of a particular IT technology sometimes gain network effects. At a broad, abstract level this means that users benefit from having others use the technology. More specifically, IT has network effect of two kinds. First, it includes direct network effects, as when I can only call you if both you and I have a telephone. Second, and perhaps slightly unfamiliarly, it captures indirect network effects. ${ }^{6}$ These arise when suppliers of content or applications respond to the number of users. There must be indirect network effects among web-enabled cell-phone users, for example, if more cell-phone-aware online content or online applications would be available as a supply response to a larger number of users. Both the direct and indirect network effects are advantages of widespread use, and the benefits of the network flow to both early adopters and late adopters once both are using the technology.

While there is considerable controversy among observers about some of the implications of network effects, there is widespread agreement that successful exploitation of network effects is a source of considerable value among users of IT.

Some IT applications are associated with substantial co-invention costs. These are costs that a user needs to bear up front, before getting any value out of the application. The co-invention costs include the costs of programming to make a technology useful in a business information system, the costs of training workers to use it, and, importantly, 
the costs of inventing a business purpose for the system and organizational change to use it effectively. While not as familiar to economists, co-invention costs are very substantial. If we look at the expenditures that are made to invent IT and IT-based applications, only a small fraction of the total cost lies in the IT-selling sectors of the economy. ${ }^{7}$

Look first at merely "technical" activities such as designing computer hardware or writing computer software. When we count up all the software that is written in connection with a single use, we find that more - far more- of technical invention, on a cost basis, is done by buyers than by sellers of IT. Much of that is applications design, applications maintenance, and systems maintenance activities. In the aggregate, buyers of IT do somewhere between half an order of magnitude and an order of magnitude more technical invention on a cost basis. ${ }^{8}$ If we then look beyond the technical costs to the business costs, i.e., the costs of inventing new uses for IT and new IT-based organizational structures that can achieve those new uses, we find even more investment by buyers. Indeed, the costs of co-inventing the nontechnical parts of applications appear to be, again by half an order of magnitude to an order of magnitude, larger than the total costs of technical invention. ${ }^{9}$ The total cost of invention in IT in use can be divided into three categories: most of it is the cost of business co-invention, the second biggest category is technical co-invention, and the smallest category is technical invention by the sellers of IT.

Since co-invention is risky, co-invention costs include costs of experimentation, costs of failed systems, and so on. There is some learning from experience, and from the experience of other users, so that coinvention costs will sometimes be declining over time (when imitation is cheaper than original co-invention). For example, current co-invention of XML-based business-to-business marketing and procurement applications by early users of that technology may lead to valuable learning that makes later imitation easier.

This imitation is itself a form of externality associated with increased levels of usage, but notice that it is distinct from the network effects in its timing. The network effects are symmetric in their timing: I can call you and you me after we both have telephones; it doesn't matter who adopted first. Imitation in co-invention is asymmetric: I can imitate you, but not you me, if you first think of a new way to use IT in business or a way to organize a firm or market to take advantage of IT.

These elements form the basic building blocks of my analysis of the adoption cycle of a particular advance in information technologies. The 
adoption cycle might take time because of three distinct bottlenecks that arise in a single user's decision to adopt. The bottleneck to adoption and value creation could be technology, business co-invention, or network effects. ${ }^{10}$ Once the user has adopted, value creation depends not only on the level of technology, but also on the success of the coinvention that has been enabled and on exploitation of network effects.

\section{These Elements in Historically Important Technologies}

To begin, let us look at the adoption of IT in commercial and business uses in the past. ${ }^{11}$ The relative importance of network effects and adjustment costs has varied across the main segments of demand and application. The segments are, in order of increasing complexity of the business application, personal productivity applications (traditionally supported by PCs), departmental computing (commercial minicomputers), organizational or enterprise computing (mainframes), and primitive interorganizational computing (traditionally supported by mainframes plus networking technologies such as EDI or SNA). Examples of these four segments might be typing a document in a wordprocessing program, processing payroll in a regional office, using a sales database to identify customers for new marketing efforts, and capturing remote data from a sales terminal or an automatic teller machine. ${ }^{12}$ In figure 4.1, I show a continuum of IT applications, and the important ways that demand and adoption vary across them, with these four segments highlighted.

The segments vary considerably in their adoption dynamics and value creation mechanisms as a result of important differences in coinvention and in network effects. Let me discuss some of the important differences and revisit the figure to summarize those for analytical purposes.

\section{Adoption Dynamics with Individual Co-Invention Costs}

On the right side of figure 4.1 are the organizational applications and simple interorganizational applications. Historically, these segments have had a high level of co-invention costs at the individual use level. Here, the user is a firm or a firm plus a few key suppliers or customers (such as travel agents in a simple interorganizational application like the networks behind airline ticket sales automation). The main applications here are business information systems in white collar bureaucra- 

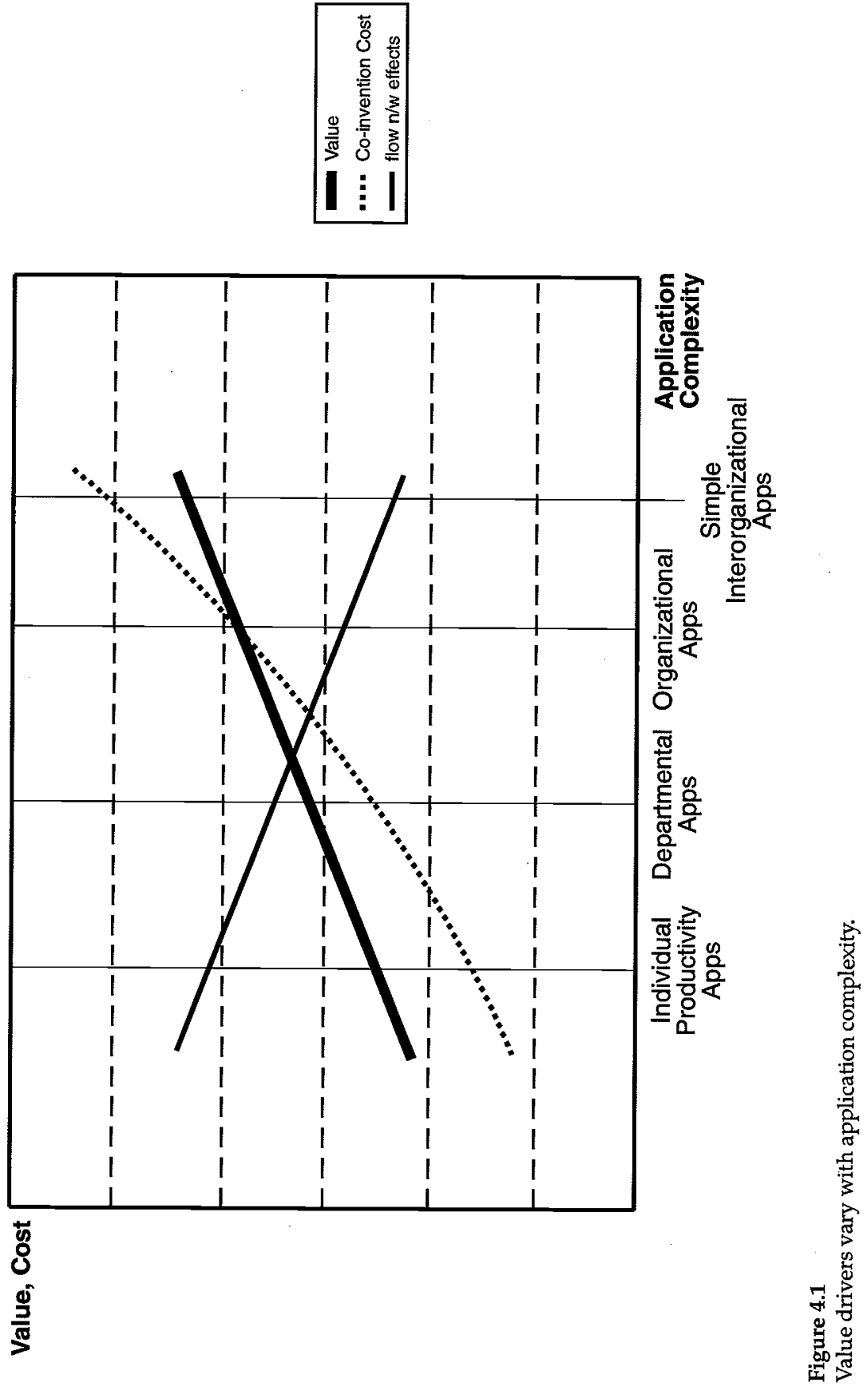
cies. The underlying technologies used in this area-powerful computers, powerful data communications, and software to take advantage of them-have undergone constant and rapid technical progress. ${ }^{13}$ A successful application in this area can shift the production function of the firm out considerably, but applications in turn call for considerable co-invention.

A substantial management research literature, and a smaller econometric one, have characterized the invention process in organizational applications. The strongest finding from the management literature is that co-invention is important, costly, time-consuming, and uncertain. In new business information systems co-invention often takes the form of linked improvements in the production process and in difficult-to-measure "soft" output attributes. This co-invention involves the translation of an underlying technical opportunity into business systems which will produce an output using fewer resources (sometimes) or a better output that customers might choose (often). The translation is itself not trivial, nor is the conceptual leap of understanding how customers will value "soft" output attributes like timeliness, convenience, flexibility, and availability. Second, new business information systems often call for changed organizations. Job definitions, division or even firm boundaries, incentive schemes, and other elements of the organization's structure and functioning will be different in the more-computerized business information system than in the preexisting one. This co-invention takes time and resources, including flashes of inventive brilliance. Inventive brilliance which changes everyone's job is not usually the most common or the cheapest resource in organizations. Nor is deep understanding of customer valuation of radical changes in "soft" output attributes. Co-invention takes time and scarce resources, and is the source of very substantial adjustment costs. IT users designing new business systems are very aware of co-invention costs, which are one of the central points of discussion in the professional and business literature of IT users. The management literature reports that businesspeople think that it is not the technology which is the bottleneck to creating valuable IT-based applications, it is co-invention of business logic or organization. ${ }^{14}$ To invent any particular new application requires both installing new technology and co-inventing new business structures. Unless both of these occur, the application will not function, or will not function effectively to deliver the desired value. Enabling technologies in general, in the short run at least, start time-consuming processes of co-invention rather than trigger immediate returns. 
The econometric literature has found several results that are consistent with that finding. ${ }^{15}$ First, it is the usual interpretation, and likely the correct one, of the very high measured rate of return to IT investment and use at the firm level. ${ }^{16}$ In a number of studies of large firms, Erik Brynjolfsson and coauthors have measured that high return. If the lower-IT firms are the ones that-so far!-are not using new IT based business co-inventions, but instead must overcome them, then that is a rationalization of the results. Perhaps more directly related to the point in this paper is the literature on diffusion of new IT technologies across large firms. Studies such as Saloner and Steinmueller (1995) and Bresnahan and Saloner (1996) find that business co-invention is a major barrier to early adoption. ${ }^{17}$

In one econometric study, Shane Greenstein and I looked at the transition, in organizational computing, to new architectures in the late 1980 s and early 1990s. This transition was quite marked, and strong enough to undercut the rents of the preexisting dominant vendor IBM. The earliest users to switch, however, were not those who had the most to gain from using the new architectures. Instead, the earliest users to switch were those who had the smallest adjustment costs at the individual user level, often lower-value applications later on. While this "reverse diffusion" finding may not be general to all cycles of new IT in organizational and interorganizational computing, the general point is that obviousness or ease of organizational implementation (low adjustment costs) as well as high value is an important determinant of early adoption.

In short, the systematic statistical literature largely confirms the quantitative importance of what the more anecdotal managerial literature had suggested. The pattern of adjustment costs can be as important if not more important in the pace of co-invention and adoption than the long run value. This characterization applies to the rightmost three segments in figure 4.1. It is by far the strongest for the primitive interorganizational applications to the far right. The reason is, these have very complex organizational co-invention costs; an application like airline-ticket seller terminals involves changing jobs and organizational structures not only for the airlines but also for the travel agents. The same effects are weaker farther to the left, in simpler departmental applications, for the same reasons, as smaller organizations can be simpler to change.

Here is a particular interplay of technical advance, network externalities, and individual adjustment costs. In organizational and simple 
organizational computing, substantial co-invention costs at the individual use level are a bottleneck. Once early adopters of any particular new technology that is valuable in this area have borne some coinvention costs, they earn substantial returns on them. Imitation by laggards follows, with the laggards taking advantage of some of what has been learned from the early adopters' struggles.

Figure 4.2 shows how these economic forces play out over time. It divides the adoption cycle for an important new enabling technology for organizational computing into three main phases. In the earliest phase, the level of information technology is not yet advanced enough to support the relevant new kinds of applications. That phase ends when technologists invent major new products or technologies which enable the new applications. That is, however, the beginning, not the end, of the economy-wide invention process. The bottleneck now becomes co-invention. This can take some time, as early adopters struggle to change products and organizations to take advantage of the new capabilities - typically half a decade. In this time period, technologists will be learning whether there is a substantial market for the new products or technology from the demand behavior of the early adopters. If they forecast a large market (including late adopters), they will put many resources into incrementally improving the technology in the direction of what the users want. At the same time, consultants, systems integrators, and applications software vendors will be learning from the experience of the early adopters. All of these advances make things easier in the third phase. Then later adopters can take advantage of what early adopters have learned about the business side of these applications. Sometimes they take advantage of this knowledge directly (computer people at the early adopters brag to the trade press and then switch jobs) and sometimes indirectly (systems integrators and consultants brag that they had a large role in the early success). This "spill-in" of knowledge lowers co-invention costs for the later adopters, and they, taking perhaps another half decade, take advantage of the capabilities of the new technology.

This description of the adoption and co-invention cycle for " $a$ " technology supporting organizational computing should not suggest that they are all alike. Many technologies are fizzles, announced as paradigm shifts but failing to draw significant co-invention. Technologies that might be useful in large organizations are at various stages of the adoption and co-invention cycle at the same time, with some getting first looks from early adopters while older ones are finishing up. 


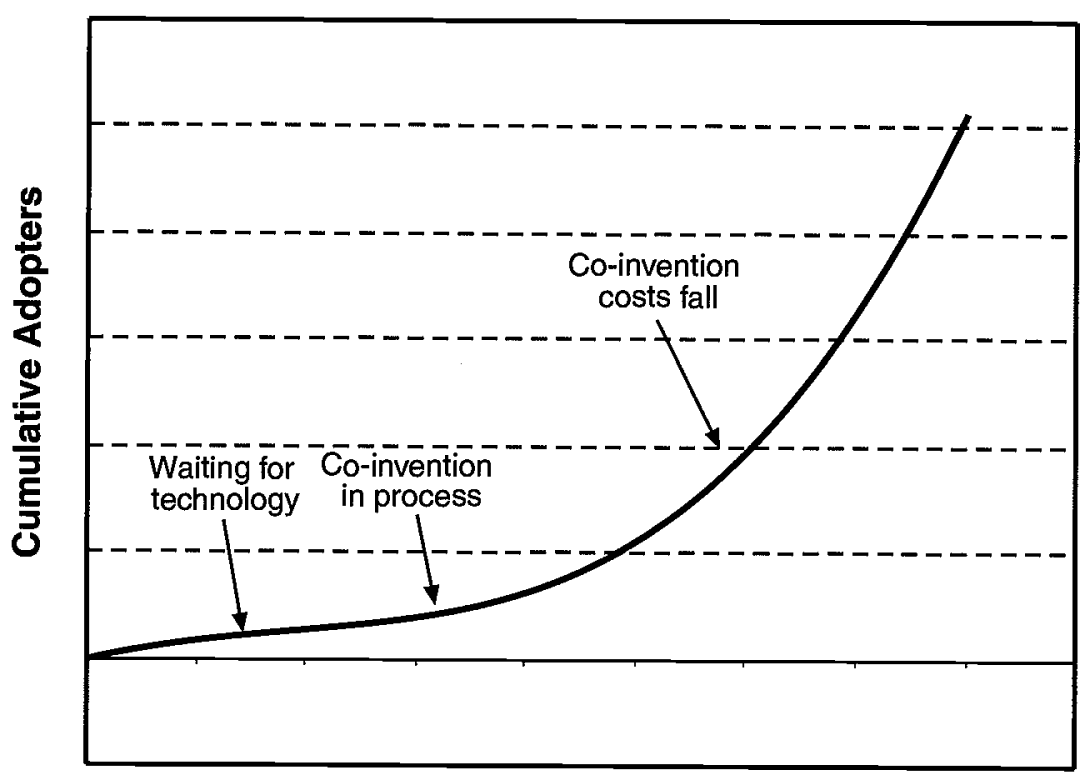

Time

Figure 4.2

Cumulative adoption with co-invention.

Growth and Welfare Economics This story of co-invention cycles offers the prospect of social increasing returns to scale. These arise through two distinct external effects.

The first external effects come from falling co-investment costs. Early users' experience lowers later users' costs of co-invention. This is a one-way externality, spilling out from early to late adopters, and there are few available institutions for internalizing it. The one-way nature of the externality creates an incentive to wait. The resulting spillout, when the externality is overcome, works to lower the business (not technical) barriers to future adoption. It is therefore the effective determinant of the pace of adoption after early uses whenever it remains true, even after some technical progress, that the barriers to adoption are business not technical.

The second externality flows through the supply of improved technology. With foresighted technology vendors, this externality flows from all adopters to each without regard to adoption dates. The rate of technological improvement will depend on the total number of adopters. The more, and the earlier, the adoption, the higher is the incentive for a technologist to invest, race, or compete for the business. This tends to lower the technical, not business, barriers to future adoption. 
Thus, it will be ineffective under the assumption that the barriers to adoption are business, not technical. ${ }^{18}$

Accordingly, for organizational applications the spillout-spill-in one-way externality is related to lowering the business barriers to adoption and is associated with weak mechanisms for internalization of the externality, while the multilateral externality is related to lowering the technical barriers to adoption, and is associated with strong mechanisms for internalization. The contrast matters. These assumptions about invention and coinvention in organizational computing vary across technologies.

A productivity surge can follow from a particular technology for organizational or interorganizational computing. After early adopters' co-inventions spill out, there will be a number of follow-on coinventions. If these are numerous, there will be a productivity surge. The timing of that surge is determined by the timing of the spillouts, however, and it tends to lag behind the period of early adoption of the technology (and the time of the greatest public attention to the technology.) Historically, these lags have been in the half-decade to decade region. There is little reason to look for a contemporary relationship between the introduction of valuable technologies for organizational computing and the resulting value creation. The productivity surge will come far later. Indeed, an IT-led productivity surge in organizational applications is likely to result as a coincidence, with several earlier technologies yielding valuable applications at once. More likely than a surge is the sustained contribution of a number of waves of technology through setting off a number of partially overlapping waves of co-invention.

\section{Adoption Dynamics with Network Effects and Low Co-Invention Costs}

Not all IT creates value as slowly as that. Other segments have far lower co-invention costs at the individual application level, and far more important flow network effects. In figure 4.1, these come to the right. Many technologies which are used by a single person have this structure. Figure 4.1 shows the PC, but other technologies such as word processing, the browser, e-mail, or instant messaging have this flavor as well. Each of these has substantial network effects. If there is a substantial body of applications, many users will want PCs, and if there is plenty of online content, many users will want browsers; and those applications and that content will be forthcoming if the technology 
is widely adopted. As long as there are plenty of others to communicate with, users will want e-mail or instant messaging. In that case, the network externalities are direct (users want to communicate with one another), while in the case of PCs or browsers, they are indirect (a large installed base of users will draw rich applications or rich content). ${ }^{19}$

While these uses and technologies have substantial network externalities, they usually do not have substantial co-invention costs at the individual level. To be sure, it takes some training to teach an experienced typist to use a PC instead of a typewriter. But those costs are tiny when compared to those associated with large organizational applications, which involve both training a large number of users in the uses of specific software (the cheap part) and redefining their jobs and the products they deliver (the expensive part). The reason is, adoption of the individual user technologies has little business co-invention associated with it. One may put a spreadsheet program on a clerk's computer without changing her job. ${ }^{20}$

The implications of this particular structure of payoffs to users is familiar from the literature on network effects. The adoption path shown in figure 4.3 has three main phases. The first phase is before the invention of the enabling technology, just as in figure 4.2. The second phase is one of waiting for network effects to take effect, and the third phase is one of positive feedback once they are taking effect. If an important motivation for users of a technology is network effects, one should expect some coordination in the adoption time, as the figure shows. That coordination can either start quickly or start more slowly, as the length of the second phase is typically not well determined.

I have drawn the third phase as quite steep, to emphasize the coordination implicit in the exploitation of network effects. This is most appropriate where individual users already have most of the technology they need to participate in the network, and it may overstate the speed of adoption when users need to acquire technology or need to switch from earlier noncompatible technology. Thus, for example, among users already having Internet connections, instant messaging could be adopted very rapidly. The PC itself diffused somewhat more slowly, even though realization of the network effects was rapid, as new users had to buy a computer to participate in the network effects. What characterizes the markets to the left in figure 4.1 is that they have low coinvestment costs; they may have other kinds of adjustment costs.

Still, the transition from a regime of not realizing network effects to one of realizing them can add considerable momentum to these mar- 


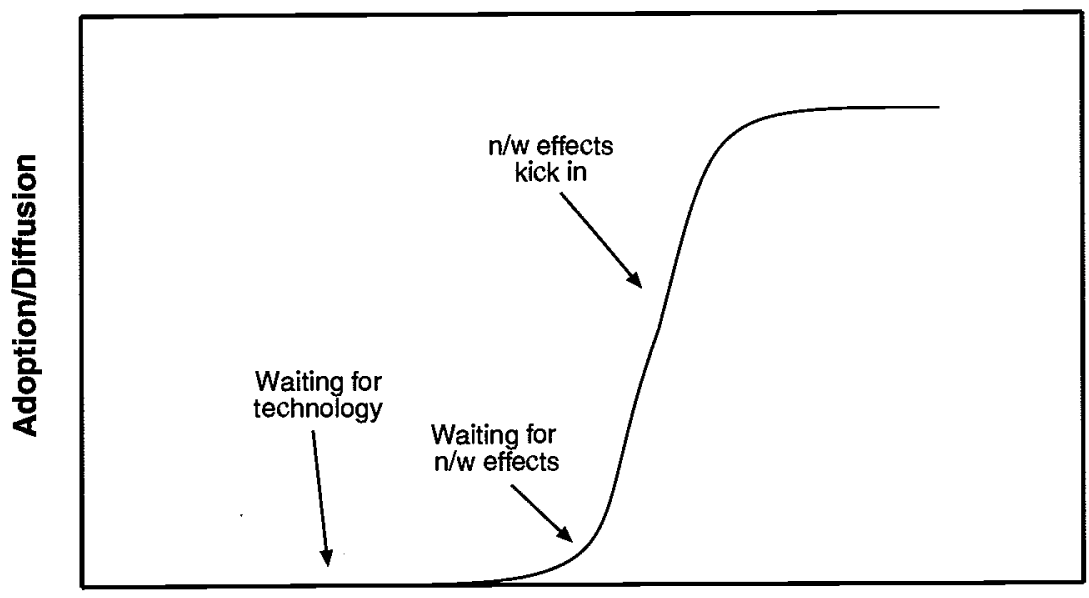

Time

Figure 4.3

Cumulative adoption with network effects.

kets. The ongoing momentum of the PC market was assured once it was realized that the spreadsheet and word processor would be the dominant personal productivity applications. A series of technical and marketing activities, culminating in the introduction of the IBM PC, put the industry in the high equilibrium in which ordinary businesspeople, not computer hobbyists, knew of the PC and its main uses. Once that was accomplished, there was ongoing technical progress which made PCs more powerful, easier to use, cheaper, and so on. This technical advance, plus the larger and larger network effects, led to a steady increase in the number of users, a positive spiral.

The key to the speed of some positive spirals for applications that go to the left in figure 4.1 is their low co-invention costs. These, in turn, tend to follow from the comparatively simple and nontransformative nature of these applications. The precise time constants associated with figure 4.3 will depend on other adjustment costs, such as the costs of obtaining technology, the costs of switching out of existing technology, etc.

\section{Complementarities across Multiple Technologies}

The last two subsections discussed the adoption and co-invention cycle of particular technologies. In both the organizational applications segments and the individual-user segments, this is an oversimplification, as technologies arrive on the scene as complements to 


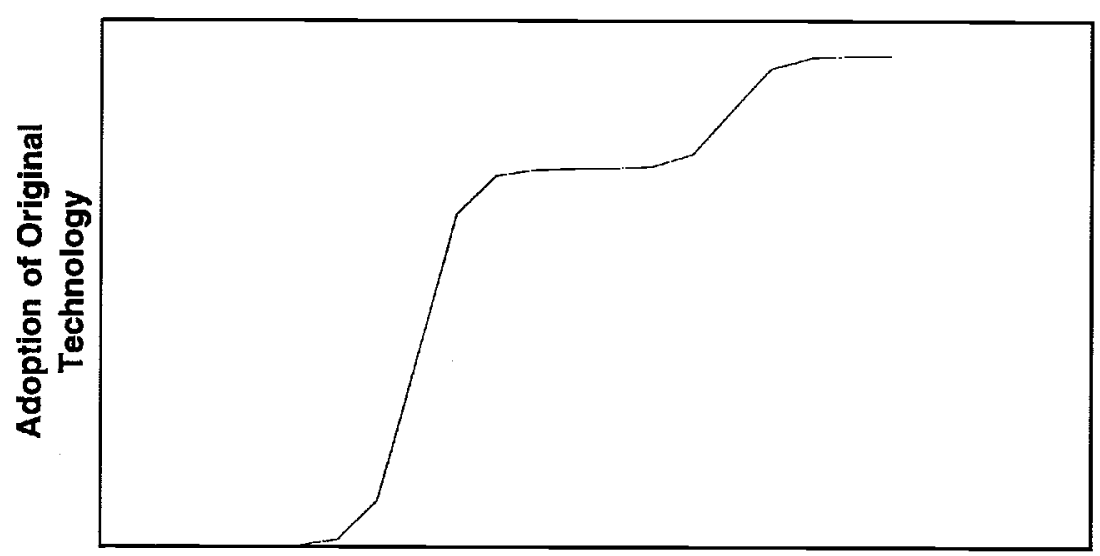

Time

Figure 4.4

Adoption with complements.

existing technologies. ${ }^{21}$ A new positive spiral in a complement tends to raise the demand for existing technology and thereby further raise value.

This situation is illustrated in figure 4.4. The figure shows the adoptions of the old technology. What happens when a positive spiral in a complementary good begins? Because of complementarity, it raises the demand for the old technology. The positive-feedback spiral of the new renews and deepens the growth dynamic of the old. By this mechanism, even more social increasing returns to scale are created. ${ }^{22}$

In the PC business, for example, advances in power and ease of use led to later invention of new applications categories, which sold more PCs. Similarly, the growing networked nature of PCs (originally motivated to economize on the then highly expensive laser printer and hard disk drive) permitted the emergence of more and more communications applications, such as e-mail. These set off their own positive-feedback loops, of course, but also cumulatively pushed out the demand side of the positive-feedback loops for PCs, to which they were strongly complementary. Perhaps the biggest of these complementary boosts to the PC positive-feedback loop was the commercialization of the Internet. But the history of the commercial PC has been marked by a steady stream of these incremental boosts from complements, a trend which shows no sign of stopping and which continues to push out the demand for the PC, thereby permitting ongoing exploitation of the base network externalities. The value of PCs and their complements in use has grown correspondingly. ${ }^{23}$ 
Organizational applications can also gain from the introduction of new complementary technology. For example, the commercialization of the Internet offered many corporations the opportunity to give employees easier access to human resources (HR) applications such as benefits through an Intranet. The HR database was preexisting, but limited in scope as only the experts in HR could access the data. Widespread access to the information is enabled by the new technology and raises the value and use of the existing databases.

\section{Summary of Variation across Applications Types}

Let me summarize this discussion by returning to figure 4.1. As we move to the right across the four segments, the value of a single adoption rises. So, too, do single-application adjustment costs at the beginning of an adoption cycle for a particular new technology. The adjustment costs likely rise more than proportionately to the value, so that both are quite large in the most complex applications. Within each segment that is organizationally complex (that is, all but the PC one), as we move toward more valuable applications we see the same thing: adjustment costs rising more than proportionately to value at the beginning of the adoption cycle. On the other hand, as we move to the right in the diagram, flow network effects decline in importance as an explanation of the pace of adoption. They decline in importance not because they go away-there are still substantial external economies even in complex applications - but because they do not remove the bottlenecks to adoption. As we move to the right in the diagram, external effects that flow only from early adopters to late ones rise in importance.

Across all the segments, there are substantial social scale economies from shared purchased technology. And there are substantial social scale economies from sharing among users. The latter, however, vary in type and implications for the pace of adoption, as we have seen in this section.

\section{The Current Technical, Co-Invention, and Adoption Situation}

The current technical situation, often shorthanded as "the Internet," contains at least two distinct applications-enabling pieces of technical progress. The first is a near-ubiquitous, cheap, and extensible networking architecture: literally the commercialized Internet. It offers the prospect for new applications in interorganizational computing. These applications cut across the boundaries of the firm (hence are 
interorganizational), and include e-commerce, supply chain management, customer relationship management, and so on.

A second piece of technical progress is in smarter, smaller, and more portable computing and communication devices-web-enabled cell phones and PDAs, for example, which may well continue the original tendency of the commercialized Internet to have a universal and easily recognizable "client," the browser. These enable applications in which mobile individuals can communicate or get information more easily, from more locations, promising more convenience and ease of use at the single-person level.

While both of these technical areas are potentially valuable, they are associated with two very different trends in applications, which are likely to be quite distinct in several regards and should not be confused. Interorganizational applications are likely to be highly complex because of co-invention. Simple adoption of mobile devices by individual workers is likely to lack co-invention costs but have network effects. The applications areas are likely to be very different in the relationship between raw technical advance in IT and the invention and diffusion of the applications it enables. They are likely to yield social increasing returns to scale by very different paths. This leads me to model the co-invention and diffusion of applications, and thus the arrival rate of social returns to innovation, very differently for the two areas. $^{24}$

The basic story is simple. I anticipate that interorganizational computing in the future may be like organizational computing or primitive interorganizational computing in the past. Critically, such applications areas as supply chain rationalization, customer relationship management, automated procurement, and other electronic automation of markets, procurement, and marketing are characterized both by very large value in the long run and by substantial adjustment costs at the individual application level in the short run. ${ }^{25}$ Second, convenient computing, by which I mean use of new, smaller devices for the purposes of an individual worker, may be like $P C$ computing in the past. It may be characterized far less by adjustment costs at the individual level and far more by the need to coordinate on moves to new technologies with substantial flow network effects. ${ }^{26}$ Thus, the two new areas appear at the far left (mobile computing) and the far right (interorganizational computing) of figure 4.1. Of course, both are also likely enhancers of existing value creation for all the existing kinds of computing technology, as in figure 4.4 . 


\section{Issues Affecting the Pace of Value Creation in Interorganizational Computing}

A number of contemporary technologies have as their main promise the creation of networked business information systems which cross the boundary of the firm. These technologies-which range from ongoing advances in areas like database management systems (now linked to Internet technologies) to new architectures for divided applications (such as XML and Java)-are numerous, important, powerful, and enabling rather than compelling of applications. Further, the new technologies are complementary to existing IT-in PCs, in servers, in database management systems, in existing data networking technologies, and so on. Many of the firms which are going to be linked by interorganizational computing have already used substantial IT in organizational computing. ${ }^{27}$

The long-run value of the use of computer and networking technologies to link organizations and to rationalize organizational boundaries is high. ${ }^{28}$ Much of employment in the rich countries is white-collar work involved in transacting. The new era of networked computing applications now beginning is likely to lead to very substantial private and public returns by reducing transactions costs. The distribution system's inefficiencies and amenability to data processing show, if not the exact form of the improvements, the potential for considerable improvements. "Reducing transactions costs," however, is not a cheap activity. It is accompanied by very substantial co-investment costs, especially those associated with changing the roles of different workers in different firms. These organizational co-invention costs are likely to loom large in the early stages of interorganizational computing.

It is reasonable to forecast that to reduce transactions costs in the deeper economic sense will involve large co-invention costs. ${ }^{29}$ These are the costs of negotiating agreements, specifying the nature of the goods and services to be exchanged, and specifying (in all but the most trivial exchanges) a number of contingencies and other contract terms going forward, and then monitoring and enforcing all the terms of the exchange, including not only completion of the exchange, but the timeliness of payment or delivery, the quality of the goods or service, and so on. ${ }^{30}$ In many cases, these transactions costs relate to the maintenance of an implicit or explicit contractual relationship over a period of time. The level and form of these deep transactions costs are, in large part, a consequence of asymmetric information. The prospective value of 
information technology lies in recording or measuring systems which are also communication systems, rendering more and more economic actions and outcomes (1) objective and quantified and (2) known to all interested parties.

Of course, this opportunity also comes with very considerable adjustment costs unless one is prepared to assume that existing trading institutions-including some with extraordinarily complex monitoring, negotiating, relationship, or incentive structures-are understood by their participants in a very deep and clear way. Without that depth and clarity, recalculating the equilibrium after adding better information through IT is difficult. It has been historically quite difficult to make such calculations within the firm in organizational computing; I would forecast that it is even more difficult to make them in market or interfirm relationship settings. I would further forecast that these calculations will vary across markets and relationships, making the coinvention costs apply at the level of the particular market or particular relationship - that is, at the level of a single new use of IT.

The speed of creation of a large amount of new social value in interorganizational computing will depend, therefore, primarily on the removal of the business co-invention bottleneck. To the extent that policies favor or restrict that economic process, they can speed or slow the creation of that value.

\section{Policy Issues}

This view of the sources of long-run value from IT and of the forces behind more rapid or slower realization of that long-run value has a number of policy implications. In this section, I look at the analytical policy implications rather than undertake analysis of specific policies.

\section{Macroeconomics and Timing}

The timing and size of social payoffs to innovations in IT affect a wide variety of policy areas. Since the greatest value from IT is created by use of technologies with considerable co-invention requirements, their timing is where we should focus. In those areas, each new IT technology pushes out the invention-possibility frontier of the economy. The pace of realization of the inventions that are enabled- 
co-invention-determines the pace of value creation. Historically, major advances that enable co-invention of highly valuable applications have set off co-invention waves that take a number of years-not months or multiple decades-to begin, and then a number of years to complete. Further, new IT technologies build on the basis of existing IT technologies, so that new enabling technologies tend to open up more valuable, but also more difficult-to-co-invent, applications opportunities. This appears to be the right approach to understanding emerging opportunities in interorganizational computing: there is valuable technology supporting new applications that cut across firm boundaries, clear economic opportunity, and the opportunity to build on existing within-firm systems, but there is also substantial co-invention to be done. Historical experience would suggest that the gains from this new technical opportunity will follow with a lag measured in the half decades.

My view departs radically from several existing views, and it is worth it to emphasize the distinction. A number of observers assume much faster creation of value from IT than I do. Observers who attribute the productivity gains of the late 1990s to Internet technologies or to the increase in the pace of technical advance in microprocessors we saw in that time period fall into this camp. The value that will be created from those advances is far more likely to come more in the new century than the old, in my view. This applies with particular force to fundamental enabling technical progress such as faster and cheaper microprocessors; the combination of faster progress there and a booming economy in the late 1990s may have arisen because that was a good time to be in the investment-goods business, rather than because contemporary technical progress caused growth with a short lag.

Another view is the hockey-stick theory, in which the returns to investment in IT remain low for decades and decades, only to turn up when-finally-co-invention of valuable applications becomes feasible or easy. This view has the time constants wrong in the opposite direction: too slow. IT is not a single technology, nor is the co-invention and adoption cycle singular or unitary. Instead, each new major advance in IT permits its own adoption cycle. What we see in the aggregate figures is the summation of dozens of little hockey sticks. At any given moment, co-inventors are utilizing valuable inventions that are a half decade to a decade old in many cases, while struggling to see the implications of newer technologies. ${ }^{31}$ 
In short, I would argue that the timing by which IT contributes to productivity growth in the future will look much like it did in the past, except that, because of increases in power, ease of use, flexibility, and so on, the scale and scope of the contribution will be larger. That is an extraordinarily positive intermediate-run aggregate growth forecast, but not one that suggests a one-time break-a surge-in the present or near future.

The macroeconomic situation in the short run has implications for the development of IT. Large markets for IT create high returns to inventors, which leads both to more competitive innovation in IT and a higher pace of invention by vendor firms. Both have considerable long-run benefits. Growth in the businesses of those who buy IT for a living (co-inventors) is an important mechanism for aggregate growth through IT.

\section{Are We Supporting the Right Innovators?}

The second set of analytical policy implications comes from the importance of co-invention in high-value applications areas. As I said earlier, co-invention is larger, in costs, than invention of IT. Further, it appears that in the applications areas where co-invention is important, coinvention and co-invention externalities are the bottleneck to realization of large returns.

Externalities form an important part of the argument for public policy in support of innovation. We argue in favor of government support of basic science by saying that the returns to that basic science are likely to be widely shared and hard to appropriate. The same argument typically militates against supporting applications.

Use of that same principle in the IT area may lead to a somewhat different view of some policy issues. There is a real externality among co-inventors, I have argued, and co-invention is a real innovative activity. Further, co-invention rather than invention is often the bottleneck to creation of social value. Yet the tax treatment, just to take one example, of co-invention is not nearly so favorable as that of many other inventive activities. This argument does not necessarily suggest that there should be a new, more favorable tax treatment for software written by MIS departments in corporations. It does, however, raise the issue of the disparate treatment of the invention costs borne by sellers and buyers of IT. It is possible that the argument for subsidy of inven- 
tion applies tightly to IT co-invention and to precommercial science which is used in IT, but not to the commercial IT sector itself.

\section{Intellectual Property Policy and Competition Policy}

With considerable uncertainty about the ideal applications of new, general purpose IT technologies and of the need for co-invention of those technologies, it is important that supply be responsive to the goals and needs of demand in IT markets. Competition among a variety of technologies is an important vehicle for achieving that social goal. Competition is not the easiest thing to accomplish in IT markets, as both individual-user adjustment costs and network effects give rise to strategic opportunities for sellers. ${ }^{32}$ Individual-user adjustment costs can become "account control" and network effects become "control of standards" - business management phrases familiar from IBM and Microsoft, respectively.

Sometimes, existing dominant firms seek to block widespread distribution of new technologies because consumer choice of those technologies might weaken their strategic position. This is the heart of Microsoft's anticompetitive acts in the antitrust case, which showed an ongoing pattern of that behavior. Competition policy then has a role to play in ensuring a level playing field. The new technologies which are competitively inconvenient to existing dominant firms include complements as well as substitutes. Microsoft, for example, sought to prevent the widespread distribution of highly popular mass market networking software supplied by other firms that was complementary to its core product, Windows. That strategic doctrine covers a broad spectrum of new technologies. Other dominant firms in IT may well make similar strategic calculations and seek to block innovative technologies, suggesting a valuable ongoing pro-innovation role for competition policy.

Intellectual property (IP) protection policy for IT industries appears to be strengthening the breadth of original technical inventors' rights and to be struggling with the definition of co-inventors' rights to business inventions. On technical inventions, it seems important to recognize that many new IT inventions are incremental improvements of older ones, and that many IT inventions are involved in a wide range of products and technologies. Excessive protection of early inventors appears to be a real danger in the current regime. On business 
inventions, it is clear that "business process" patents have been very difficult to set in standard patent categories. Protection has been granted for inventions which seem to outsiders to be stunningly obvious, while the general category has no clear guidelines.

It is not clear to me that co-inventors are overprotected in the aggregate, however. For example, enforcement of IP rights by content providers against peer-to-peer ( $\mathrm{P} 2 \mathrm{P})$ networks (surely the most advanced mechanism for delivery of copying services ever invented) may slow down their advance. The issue here is that technical change undermines existing business models; Napster is bad for Hollywood, as it is a cheaper distribution system for music. Accordingly, P2P takes on, through the legal system, some of the adjustment-cost dynamics of electronic commerce. In particular, it takes on a channel conflict problem. Cheaper distribution is good for artists, good for listeners, but changes the allocation of rents in a way that is bad for the existing distribution system. Until it becomes obvious to artists how to take advantage of the new technology to escape the (substantial) taxation of their artistic labor imposed by Hollywood, one role of IP enforcement in this area will be to strengthen the grasp of the dead hand of the past.

With IP both overprotecting some co-invention and making it possible for existing forces to block other co-invention, we should recall that IP law is designed to create tradable property rights, and multiple, incomplete, or confused rights that undercut the clarity of ownership create needless transaction cost. Bad IP policy can raise the costs of innovation.

\section{Conclusion}

Internet technologies and other advances in IT promise a very large social return in the long run. That return will be delivered, however, only after a new round of co-invention of applications. IT does not directly shift the production-possibility frontier of the economy, but rather shifts the invention-possibility frontier. Currently available IT, plus forecastable improvements, enables but does not compel co-invention which will improve the routines, services, and organizational structures of white collar bureaucracies for buying and selling. The valuable IT applications of the late 1990s were not immediately and directly caused by IT improvements of that era, but resulted from co-invention that followed earlier ones with a lag. Looking forward, the inventions that have been enabled by recent IT technical progress are likely to be 
highly valuable, but they are unlikely to arrive quickly, while others that arrive quickly may lead to less value, as there is no single stock of "IT capital." The opportunity for policy to influence the rate of arrival of the valuable applications remains, for the incentives that will determine the rate of realization of the promise of Internet technologies will play out over a long period of co-invention.

The key implications arising from co-invention and/or network effects is the potential for social increasing returns-the ability to generate sustained welfare increases through technological innovation. However, there is no reason to believe that the benefits arising from co-invention and/or network effects will be realized at anything like the optimal level without careful attention to the policies and institutions affecting IT vendors and buyers.

\section{Notes}

I thank the conference organizers for insightful comments but retain responsibility for all errors. E-mail: tbres@stanford.edu. Papers:http://www.stanford.edu/ tbres/.

1. I follow a substantial literature in distinguishing between raw IT invention, which enables valuable applications, and users' co-invention, which creates the applications themselves. See for example Barras (1990), Bresnahan and Greenstein (1997), Davenport and Short (1990), David (1990), Malone and Rockart (1991), Scott Morton (1991), and Zuboff (1988).

2. Cf. Bresnahan and Trajtenberg (1995) and Helpman and Trajtenberg (1996).

3. I mean "productivity" in a sense largely unrelated to the productivity statistics we now read, as most of the gains from IT are unmeasured. More in note 24.

4. While the discussion in this section is informal, the appendix to the online version of this paper has a corresponding formal model.

5. First, it could be the supply behavior of a monopolist selling the new technology. Second, it could be the aggregate of several competing suppliers, or the result of a race to be the supplier of choice. Third, it could result from interactions with sellers of existing technologies, who might either encourage the new technology or attempt to block its widespread distribution (as Microsoft did with several Internet-related technologies whose competitive implications it did not like).

6. See Katz and Shapiro (1994) for definitions.

7. These remarks draw on Bresnahan (2000), which has definitions and sources. The underlying data behind this particular remark are surveys of expenditures on purchased technology vs. technology built in-house in the corporate sector. Thus, this part is literally cost accounting.

8. I emphasize the cost basis because this does not establish that buyers accomplish more technical progress than sellers do. Sellers achieve enormous economies of scale by shipping the same hardware or software design to millions of buyers (this is an 
important part of the equilibrium that defines the boundary, in invention space, between buyers and sellers) and thus may be doing "more" technical progress in whatever the appropriate physical units might be.

9. This result appears both in studies of the demand for IT, such as Bresnahan and Greenstein (1997) and Ito (1996) and in studies of the firm-level return to IT investments, such as Brynjolfsson et al. (1996, 1997, 2000). This is less of a literal cost accounting exercise and more an interpretation by these authors of a substantial omitted asset associated with new IT applications.

10. To say that one of these is the bottleneck means no more than that the other two are over the relevant thresholds and that the third is not.

11. That leaves out engineering or technical computing, which has less co-invention costs in an adjustment cost sense, and also smaller network effects.

12. The segment boundaries are not important here; what is important is that more complex applications have a different co-invention process and are supported by distinct IT.

13. Sometimes major branches of computing are categorized by the kind of computing used, so that organizational computing was for years called mainframe computing. I wish, however, to do a categorization by type of $u s e$, not technology. The partial replacement of mainframes by smaller computers in many corporate applications is an example.

\section{See sources in note 1 above.}

15. Systematic statistical work on shifts in computing architectures has found substantial adjustment costs (Ito 1996, Bresnahan and Greenstein 1997), and the case literature on IT implementation highlights difficulties in implementing concurrent organizational changes (e.g. Friedman and Cornford 1989, Hubbard 1998, Zuboff 1988). Moreover, there is additional evidence that the monetary and nonmonetary costs of these adjus tments are larger than the capital investments in many cases (Brynjolfsson and Hitt 1996, Brynjolfsson and Yang 1997, Bresnahan 2000).

16. Because co-invention costs, and the success of attempts at co-invention, vary across firms, there is substantial heterogeneity in the use of IT in the cross section of firms at any given moment. The heterogeneity is driven, in no small degree, by differential success in co-invention and differential costs of co-invention. Cf. Bresnahan and Greenstein (1997) or Brynjolfsson, Bresnahan, and Hitt (2000). For modeling purposes in this paper I shall be more interested in this heterogeneity ex ante than in the uncertainty of co-invention, which I shall treat as an adjustment cost to the user.

17. The implicit model in the businessperson's head is near-Leontief, with both knowledge of (raw) technology (at least at some level) and knowledge of the business need or the organization (at least at some level) both needed to create valuable applications. The businessperson will report that "technology is the bottleneck" if they understand the business purpose of a new application and the organizational implications, but cannot implement it with existing IT. They will report that "technology is not the bottleneck" if the level of (raw) technology is over the threshold but the level of business understanding is not.

18. Here I am assuming a brighter line between "business" and "technical" invention than really holds. The important economic point, however, is that not all of the invention that goes on in making organizational applications can easily be turned into a GPT. Some parts of it, and these are systematically the "business" or "organizational" parts, remain idiosyncratic to individual uses and require use-by-use co-invention. 
19. The sense of network externality used here is unrelated to the proprietary technology of any one PC, browser, e-mail system, or Instant Messaging system. At this stage, all that strategic supply is in the background, and we are only concerned with the externalities among users. Thus, the discussion is consistent with any of the following: a monopoly in a proprietary technology, competition within an open standard, races to establish a standard, or standards in competition serving different bodies of demand.

20. Use of these technologies may very well lead to more and more intelligent applications, ones that ultimately lead to organizational change and more value, especially when the use is linked to larger systems. (Think of the clerk having yesterday's sales database put into her spreadsheet.) That, however, does not hold up diffusion of the individual-user technology itself. Indeed, the larger systems have much of the same kinds of learning-by-using associated with them; the issue is finding something to do with them at the beginning so that there is some using to base the learning on.

21. A new technology which is a superior replacement to existing technologies and which enables new and better applications should be analyzed using the framework of those two sections.

22. Not all new IT is complementary for old technologies, so the opposite case of replacement rather than enhancement occurs as well.

23. Ongoing growth in the demand for PCs has meant in practice that demand for the two main proprietary technologies underlying the dominant PC platform, the Windows operating system and Intel architecture microprocessors, has been growing as well. Accordingly, the tendency of both Microsoft and Intel to use forward-pricing rules to exploit their monopoly positions, rules which take into account the future demand for their products associated with the development of new complements, has been richly rewarded.

24. I treat increases in the ability of the economy to satisfy human wants with a given body of resources as the definition of technical progress at the economy-wide level, and thus label any of a wide variety of phenomena as "improvements in productivity" even if they do not lead to increases in measured productivity. This leads me also to treat invention of new applications and other co-invention by users of IT as improvements in productivity, though I distinguish them from engineering-sense (or raw) technical progress embodied in IT itself.

25. Here a "user" making a single application is a market or a supply chain. The "user" is coextensive with the economic benefits and costs of a particular application of technology, which here is not the firm but the cluster of firms that participate. When I say that the adjustment costs at the individual level are large, I mean at the level of an individual market. When I say that network effects are small, I mean network effects across markets. Obviously, there are network effects in using compatible technologies for all the participants in a particular automated market.

26. This characterization need not apply to all uses of mobile devices, some of which may serve the purposes of the individual's employer as parts of complex organizational or interorganizational applications. The characterization applies to the application of the device by the individual user for her own purposes.

27. In addition to the business co-invention costs I emphasize, there will be substantial technical invention and co-invention costs of connecting these "legacy systems."

28. Cf. Bresnahan and Saloner (1996) and Litan and Rivlin (2001) for analysis of the long-run prospects. But see Gordon (2000) for a dissenting view. 
29. These are transaction costs in the sense of Williamson. Recent treatments of the economics of organizations (Milgrom and Roberts 1992) and the economics of market institutions (Greif, Milgrom, and Weingast 1994) focus on the importance of imperfect information as a driver of these transaction costs.

30. See, e.g., Garicano and Kaplan (2000).

31. Both of these views, the hockey-stick one and the very fast one, arise from asking the aggregate productivity statistics to do more than they can do. There is considerable realization of gains from IT that is not measured in the productivity statistics, and some that is so measured, before and during the late 1990s.

32. Cf. Bresnahan and Greenstein (1999).

\section{References}

Barras, R. 1990. "Interactive Innovation in Financial and Business Services: The Vanguard of the Service Revolution." Research Policy, no. 19.

Bresnahan, Timothy. 2000. "The Changing Structure of Innovation in the Computer Industry." In D. Mowery et al., eds., U.S. Industry in 2000: Studies in Competitive Performance. Washington DC: National Academy Press.

Bresnahan, Timothy, and Shane Greenstein. 1997. "Technical Progress and Co-invention in Computing and in the Uses of Computers." Brookings Papers on Economic Activity, Micro: $1-83$.

Bresnahan, Timothy, and Shane Greenstein. 1999. "Technological Competition and the Structure of the Computer Industry." Journal of Industrial Economics 47(1): 1-40.

Bresnahan, Timothy, and Garth Saloner. 1996. "Large Firms' Demand for Computer Products and Services: Competing Market Models, Inertia, and Enabling Strategic Change." In David B. Yoffie, ed., Colliding Worlds: The Merging of Computers, Telecommunications, and Consumer Electronics. Cambridge, MA: Harvard University Press.

Bresnahan, Timothy, and Manuel Trajtenberg. 1965. "General Purpose Technologies: 'Engines of Growth'?" Journal of Econometrics 65(1): 83-108.

Brynjolfsson, Erik, and Lorin Hitt. 1996. "Paradox Lost? Firm-Level Evidence on the Returns to Information Systems Spending." Management Science 42(4): 541-558.

Brynjolfsson, Erik, and Shinkyu Yang. 1997. "The Intangible Costs and Benefits of Computer Investments: Evidence from Financial Markets." Proceedings of the International Conference on Information Systems. Association for Information Systems.

Brynjolfsson, Erik, Timothy Bresnahan, and Lorin Hitt. 2000. "Information Technology, Workplace Organization, and the Demand for Skilled Labor: Firm-Level Evidence." Quarterly Journal of Economics.

Davenport, Thomas, and James Short. 1990. "The New Industrial Engineering: Information Technology and Business Process Redesign." Sloan Management Review 31(4): 11-27.

David, Paul. 1990. "The Dynamo and the Computer: An Historical Perspective on the Modern Productivity Paradox." American Economic Review 80(2): 355-361.

Friedman, A., and D. Cornford. 1989. Computer Systems Development: History, Organization and Implementation. Chichester, U.K.: Wiley. 
Garicano, Luis, and Steven Kaplan. 2000, November. "The Effects of Business-toBusiness E-Commerce on Transaction Costs." Working Paper no. W8017. Cambridge, MA: National Bureau of Economic Research.

Gordon, Robert J. 2000, August. "Does the 'New Economy' Measure Up to the Great Inventions of the Past?" Working Paper no. 7833. Cambridge, MA: National Bureau of Economic Research.

Greif, Avner, Paul Milgrom, and Barry Weingast. 1994. "Coordination, Commitment, and Enforcement: The Case of the Merchant Guild." Joumal of Political Economy 102(4): 745-776.

Helpman, Elhanan, and Manuel Trajtenberg. 1996, September. "Diffusion of General Purpose Technologies." Working Paper no. W5773. Cambridge, MA: National Bureau of Economic Research.

Hubbard, Thomas N. 1998. "Why are Process Monitoring Technologies Valuable? The Use of On-Board Information Technology in the Trucking Industry." Working Paper no. W6482. Cambridge, MA: National Bureau of Economic Research.

Ito, Harumi. 1996. "Essays on Investment Adjustment Costs." Ph.D. Dissertation, Stanford University.

Katz, Michael, and Carl Shapiro. 1994. "Systems Competition and Network Effects." Journal of Economic Perspectives 8(2): 93-115.

Litan, Robert, and Alice M. Rivlin. 2001. Beyond the Dot.Coms: The Economic Promise of the Internet. Washington DC: Brookings Institution Press.

Malone, Thomas, and Jack Rockart. 1991. "Computers, Networks and the Corporation." Scientific American 265(3): 128-136.

Milgrom, Paul, and John Roberts. 1992. Economics, Organization and Management. Englewood Cliffs, NJ: Prentice Hall.

Saloner, Garth, and W. Edward Steinmueller. 1995, June. "Demand for Computer Products and Services by Large European Organizations." Research Paper Series, no. 1370. Stanford, CA: Stanford Graduate School of Business.

Scott Morton, Michael. 1991. The Corporation of the 1990s: Information Technology and Organizational Transformation. Oxford, U.K.: Oxford University Press.

Zuboff, Shoshana. 1988. In the Age of the Smart Machine: The Future of Work and Power. New York: Basic Books. 

, 